\title{
An Overview of Digitalisation in Conventional Supply Chain
}

\section{Management}

\author{
Sarath Menon ${ }^{1, *}$, Satya Shah $^{2}$ \\ ${ }^{1,2}$ Off Campus/Institute of Management, University of Bolton, United Kingdom
}

\begin{abstract}
Rapidly growing technology and a digitally focused world have opened the door for a new wave of automation to enter the work force in the industry. Industry 4.0 plays a vital role in Supply chain management (SCM) which requires constant research and improvements due to high demand to meet their global competitive markets. As part of achieving this high demands, SCM has been incorporating the latest evolving technologies by digitalizing and automating themselves to increase their financial profits and competitiveness in the market. This paper aims to have a review on Supply Chain Management (SCM) and latest technologies in Industry 4.0 revolution.
\end{abstract}

\section{Introduction}

Supply chain management has been defined as the integration of activities like sourcing of materials, transformation into intermediate goods and final products before delivering them to the customer [1]. Supply chain is a network in an Organisation that is used deliver the end product or services to the customers with a supply chain management (SCM) which involves different process from sourcing of raw materials, engineering process flow including design, planning, production, control and monitoring of supply activities with objective of creating net value, competitive infrastructure design, handling logistics, synchronising supply with demand and performance assessment [2]. The primary objective for existence of any supply chain is being satisfactory to customer needs by maximising the overall performance, with more efficient design processes, improved quality or reduced costs, faster delivery. Basically supply chain functions to achieve a cohesive and high performing business design structure by integrating with primary responsibility for linking major business functions and business processes within and across companies [3]. Supply chain management with strategies management activities, and manufacturing operations, drives coordination of activities and processes within and across marketing, product design, sales, finance and info technology that leads for a better efficient results.

Utilisation of digital supply chain in an Organisation aids to provide insights for an enhanced efficiency those assists to create an increased economy. Supply chain technologies validates its performance with a better plan, design, and managing the flow of goods or orchestrate the participants in the ecosystem [4]. It is all about organising a string of pursuits that are connected with synchronising, administering and planning the transfer of raw elements, parts and products from the manufacturer to the end - customer [5]. This paper explains the key literature on the benefits of digitization within supply chain through the integration of traditional methods to that of new digital supply chain. The paper focused with the use of an existing case study environment.

\section{Literature Review}

During the literature review the researcher has used the keywords: Digital supply chain; manufacturing; circular economy; SME's and industry 4.0 and identified around 2500 literatures in google scholar within the period of 2011-2018 during which the industry 4.0 has emerged. From the 2500 identified literatures the researcher have again scrutinised and identified 252 literatures by avoiding the books, and smart city. In this paper the researcher seeks to outline the conceptual framework of the research by presenting a review of trends, drivers and hurdles of conventional supply chain and latest technologies in industry 4.0. In particular, the evolution, strategy and analysis, new trends of industry 4.0 , are reviewed.

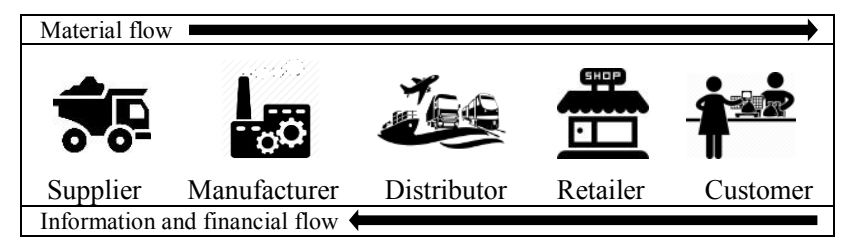

Fig. 1. Conventional supply chain (CSC)

A typical supply chain is basically a network of raw materials, resources and services processing links along with the traits of supply, demand and transformation as shown in figure 1 [6]. The traditional supply chain is a process which involves transformation of raw materials to a physical product which is delivered to a customer. There are number of steps involved in a traditional supply chain process which involves:

- Sourcing of raw materials,

- Acquiring materials,

- Manufacturing,

- Distributing,

- Selling to end customer. 
An initial step in a supply chain system is the sourcing of the raw materials which continue to second step of acquiring of material by the manufacturing company that may be a straightforward process [7]. Sometime the sourced raw materials may have to undergo some process before the materials can be acquired by the manufacturer. After acquiring of material by the manufacturer, they undergo further process or assembly of product. Once these processes are complete, the end product will be distributed by the manufacturer to their consumers. Usually, these consumers are not the end customer of the product, they plays a middlemen role between the manufacturer and end customers [8]. Conventional supply chain system is convergence of numerous disciplines which equally has "hard" (i.e., technical) and "soft" (i.e., people) area, including marketing, procurement, operations, research, social psychology, transportation management, robotics, engineering. Even at present the social network analysis claims its natural application on soft side of SCM, which helps to understand, the translation of different patterns of individual relationships to competitive advantages through scattering of resources, opportunities of social control, aid \& coordination and so on [9]. Some of the common uncertainties and challenges in SCM are given table $1[10]$.

Table 1. Challenges of conventional supply chain

\begin{tabular}{|l|l|}
\hline Challenges & Description \\
\hline $\begin{array}{l}\text { Response } \\
\text { time }\end{array}$ & $\begin{array}{l}\text { Transformation of data and information } \\
\text { resources in between the individuals are } \\
\text { quite slow, and rather focus on a linear } \\
\text { model which results in long response } \\
\text { time. }\end{array}$ \\
\hline $\begin{array}{l}\text { Conflicting } \\
\text { priorities }\end{array}$ & $\begin{array}{l}\text { Supply chain often operate individually } \\
\text { with their own set of goals which } \\
\text { collaborates at the top level, but } \\
\text { insufficient solidarity may results in } \\
\text { conflicts. }\end{array}$ \\
\hline $\begin{array}{l}\text { Inept } \\
\text { fulfilment } \\
\text { model }\end{array}$ & $\begin{array}{l}\text { The end user experience certainly drives } \\
\text { the supply chain models but the } \\
\text { conventional supply chains models are } \\
\text { inefficient to meet the interest of their } \\
\text { customer for multiple channel access to } \\
\text { purchase, take delivery of their product at } \\
\text { any time, from anywhere. }\end{array}$ \\
\hline $\begin{array}{l}\text { Steadfast } \\
\text { Technology }\end{array}$ & $\begin{array}{l}\text { The digital supply chain technology } \\
\text { features are falling behind the highly } \\
\text { demanding and progressing technology } \\
\text { and digitally focused customer } \\
\text { experience. }\end{array}$ \\
\hline $\begin{array}{l}\text { Lack of } \\
\text { advanced } \\
\text { multi- } \\
\text { functional } \\
\text { skills }\end{array}$ & $\begin{array}{l}\text { chain lacks skill for cross-function, which } \\
\text { loses the opportunity to effectively use } \\
\text { the data in a cross functional system } \\
\text { which results in operational and financial } \\
\text { decisions. }\end{array}$ \\
\hline $\begin{array}{l}\text { Data provided by the traditional supply } \\
\text { chain technology steers to inaccurate } \\
\text { plans, higher fulfilment costs and } \\
\text { difficulty in prediction of arising }\end{array}$ \\
\hline
\end{tabular}

\begin{tabular}{|l|l|}
\hline \multirow{7}{*}{ Adaptability } & $\begin{array}{l}\text { problems due to its exposure limitation at } \\
\text { end to end supply chains, products and } \\
\text { shipments points. }\end{array}$ \\
\hline $\begin{array}{l}\text { Many Organisation has developed and } \\
\text { rely upon their unique system processes a } \\
\text { "secret sauce" that may in the form of } \\
\text { special method to manufacture goods, or } \\
\text { a strategy for smart material sourcing or a } \\
\text { unique mode of serving customer orders. } \\
\text { Adaptability is the necessity of an } \\
\text { Organisation to effectively redesign their } \\
\text { system to that unique system process to } \\
\text { achieve competitive advantages. }\end{array}$ \\
\hline $\begin{array}{l}\text { Agitability is necessity to react quickly to } \\
\text { the changing core business models or to } \\
\text { the market conditions which force the } \\
\text { supply chain managers to hit the } \\
\text { continuously changing targets which can } \\
\text { be due to some merging off or } \\
\text { acquisitions, introduction of new } \\
\text { products, entry of e-commerce or some } \\
\text { external factors like new tax regulations, } \\
\text { demands, expectation of customer service } \\
\text { and so on. }\end{array}$ \\
\hline
\end{tabular}

\subsection{Industry 4.0- a digital revolution}

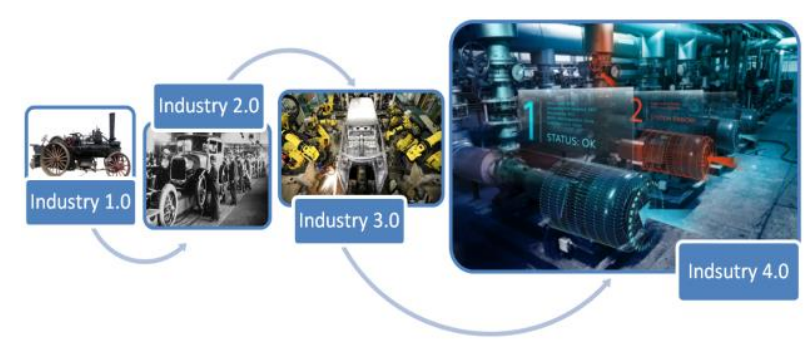

Fig. 2. Evolution of Industry 4.0

A transformation into autonomous production as shown in Fig 2 was brought very first by steam and water energy (Industry 1.0), followed by electrification (2.0), far more recently by the digital computer system (3.0). Now in Industry 4.0, organisations are positioning themselves with digitization to their end consumers using customer experience, digital marketing and ecommerce [11]. Ultimately, based on the latest technological advancements a new business model designs up by undergoing transformation in each facet of a company with integration of research and development, manufacturing, marketing \& sales, and other internal operations. Virtually, driving towards a complete new digital ecosystem [12].

This technology enables for a paperless business deals by networking between the companies and individuals interested in it. Implementation of a broad variety of digital technologies will entirely automate the conventional supply chain system that eliminates the manual data which, results in reducing the human random error [13]. The key technologies of industry 4.0 are briefly discussed below. 


\subsubsection{Big Data}

A substantial amount of velocity, volume and variety of information resources which calls for an innovative form of information and cost effective processing which delegates an improved decision making and process automation is branded as Big Data [14]. One of the main goal of big data and analytics is to make full usage of the data to improve productivity, by providing "the right information, for the right user, at the right time". Its analytics enable for a greater deep insights as well as visibility for supply chain. Big data analytics refers to the processes of examining and analysing huge amounts of data with variable types to draw conclusion by uncovering hidden patterns and correlations, trends, and other business valuable information and knowledge, in order to increase business benefits, increase operational efficiency, and explore new market and opportunities [15]. The application of big data and big data analytics in supply chain management area includes: Strategic sourcing, supply chain network design, product design and development, demand and planning, procurement, production, inventory, logistics and distribution and supply chain agility \& sustainability. Improving big data analytics capabilities will have a big impact to enhance the performance of the Organisation by creating new product \& services, providing better customer services, increase sales and revenue and expanding into the world market.

\subsubsection{Internet of Things (IOT)}

Internet of Things (IoT), is one of the latest technology that provides a model shift in supply chain management and several areas. It has the ability to lead the supply chain communications to advanced levels and offer immense openings to tackle SCM more efficiently. It equips supply chain with next level of visibility, dexterity and flexibility to subsist with various challenges in supply chain and offers an unprecedented perceptibility to different aspects of supply chain [16]. IoT enables constructive collection and analysis of data reports from smart objects which can provide with practical statistics or information like early warnings of internal and external situations that require remediation and many more. IoT results in reduced time between data capture and decision-making that enables supply chains for a faster reaction and adopting the changes in real time that results in new levels of agility, efficiency and responsiveness never experienced before. IoT enables better remote management of supply chain operations and can provide more accurate information for more effective decision-making [17].

\subsubsection{Cloud System}

Cloud computing technology is a structural system design which allows universal access to shared pools of configurable program of resources typically over the internet with an extended level of services that could be swiftly equipped with minimal amount of management efforts. Instead of disbursing resources on computer infrastructure and maintenance, third party cloud system allows their Organisations to focus on their core businesses. [18]. Cloud computing claims that it allows enterprises to get their applications up and running faster, with improved manageability and less maintenance, which enables the IT teams to more rapidly adjust the resources to meet fluctuating and unpredictable demands and helps their companies to avoid or minimise on their up-front IT infrastructure [19]. The technology typically provides a "pay-as-yougo" model, which could even lead to an unexpected operating expenses if administrators are not familiarised with cloud-pricing models.

The accessibility for a low cost computer and storage devices, wide spread adoption of virtualization, service oriented architecture, autonomic \& utility computing with high-capacity networks has led to an upturn in cloud computing with launch of Amazon EC2 platform in 2006 [20]. The cloud computing technology helps Organisations to achieve major benefits from crucial market trends which redefines in the traditional supply chain networks like [21],

- Volatility is the new normal

- Surging data volumes

- Industrial grade digital technology

- Visibility to end-to-end process

\subsubsection{Robotics}

Autonomous robots are the latest technology in robotics. These technological products are programmed and designed to execute the tasks with very little to no human interaction or even any involvement. The latest technology of robots considerably differ in their design, sizes, intelligence, dexterity, operations, mobility and price. Robots now varies from automated robotic processes to A.I equipped flying vehicles [22]. Autonomous robots are able to recognise and learn from their surroundings and make decisions independently. The technology is particularly utilised for an improved efficiency in routine operations of manufacturing and warehousing plants by working side by side with humans with enhanced accuracy and speed which even helps to reduce employee risk in dangerous processes. As the hardware and software in autonomous robots continues to improve, they could provide a competitive advantage to employers within the next 5 to 10 years [23]. They are becoming sophisticated and faster with required safety provisions which allow them to work collaboratively with humans with more advancement in its agility, sensors, trainability and artificial intelligence [24].

\subsubsection{Sensors and Geolocations}

Global positioning system (GPS) technology functions as a mainstream application that assists consumers for an improved navigation for journeys. GPS technology has helped the manufacturers keep track of trucks or to monitor the status of large containers in transit. Although, experts say the concept still remains to be limited in use in manufacturing supply chain, primarily deployed in strategic planning applications where there are still some delays being attributed. Cost of GPS' continues to be higher compared to some other AIDC 
solutions like RFID and bar codes. Integrating the actual resources of the technology experts says it lacks the accuracy for locating products in an enclosed space [25].

Smart sensors allow to revolutionise the world into digital insights which paves way to create new technological ideas in supply chain. Smart sensor computing have strengthened substantially it abilities, which allows the data processing and analysing at or near the source ("edge computing") resulting in reduced amount of data movements between the platform and device [26]. Moreover, the latest technology of Micro Electro-Mechanical System (MEMS) is more compact where the higher functioning smart sensors have been incorporating microelectronic functions in minimal space.

\subsubsection{D Printing}

A decade ago, consumers wait for their product as per the required lead times by the company, but now companies such as Amazon, Walmart etc. has influenced consumers to have their purchase decisions based on how speedily they will receive the product [27]. The technology of 3-D printing is being used in additive manufacturing and rapid prototyping where a 3dimensional object is produced as per design by adjoining the materials together by knitting or solidifying it using computer controls [28]. Digital model data from a 3-D model or from an AMF (additive manufacturing file) are typically used to create the resultant product of any geometry. Thus, it builds the product by progressively adding material layer by layer unlike material being removed from a stock in the conventional machining process [29]. The demand economy is buckling every sector and inspiring those in the supply chain and manufacturing fields to be more innovative than the past. Nowadays companies are into 3-D printing for instant creation of their products in order to stay competitive in their market.

\subsubsection{User Interface}

The user interface UI is the work space where human machine transpiring interaction takes place in the industrial design field. The interface simultaneously allows the machines to feedstock the resourceful information that aids operator decision making process while the machine is processing and controlled efficiently by the human end. One of the broad concept of user interfaces includes the collaborative aspects of hand tools, computer operating systems, heavy machinery operator controls and process controls. While creating user interfaces the applicable design elements implicates or associates to such disciplines like ergonomics and psychology [30].

Creating a process of user interface designs is an ominous task by all measures as it requires an efficient multitasking, a pivot area for all Organisational operations. UI design is envisaged to enable its users to do moreover better time efficient modes and it should not only to cling to the three radical concepts like Organising, Economising and Communicating [31].

\section{Conclusion}

It is evident from the literature that digitisation and automation of supply chain management offers unlimited possibilities of exploration as the market dynamics widely vary in economies, regions, climate zones, time zones, political systems, countries, population demographics, and so on. The field of digital supply chain continues to enhance as the world is integrated into one great global marketplace, and the researchers are faced with new scenarios from time to time [32]. Some of the future research scopes of development in smart supply chain are highlighted as:

- Circular supply chain/sustainable supply chain

- Wearable devices

- Logistic visibility

- Manufacturing Execution Systems (MES)

- Smart factory

- Autonomous vehicles

It is evident from the literature review that SME (small and medium enterprises) companies have yet to succeed in creating a true digital supply chains due to its extremely complex organism. During the literature review the researcher has understood that even yet many of the required applications in industry 4.0 are not widely used. The latest technological advancements discussed in this paper makes the smart supply chain more efficient, effective and flexible than conventional supply chain by digitisation and automation. Different companies are implementing DSC at varying speed which will results in a radical change over the next five years [33]. First row of companies to implement the latest DSC will absolutely achieve a difficult-tochallenge advantage in the race to Industry 4.0, and will influence or be able to set, their particular industrial technical standards that may results in greater efficiencies with no means of any limitations. This advanced technology opens up for many new business design models and generate revenue streams.

An operational technology that provides a high level of service, where a customer can always find their required products within the cost they are willing to incur, and self-select the level of delivery service is the primary goal in a supply chains management [34]. Some companies requires different efficient models of supply chain design and processes to support their innovative technology where the scope, use of scale, and service through unique structural models and partnerships, enables them to provide convenient quality selection of products and services with competitive pricing strategy. By focusing supply chain initiatives on specific goals with reinforcement and support to long-term competitive business strategies for companies to achieve excellence within the supply chain [35].

As seen through earlier research studies the key design factor in supply chain is innovation. Companies could find themselves in losses and face bankruptcy if they don't embrace now for innovations and implement themselves with technological advancements [36]. In 
some respects, supply chain excellence protects established market leaders from highly innovative upstarts because the art of creation and shipping products around the world requires a degree of "old world" processes with advanced technology [37].

\section{References}

1 Abbasi, M. and Nilsson, F, "Themes and challenges in making supp.ly chains environmentally sustainable", Supp.ly Chain Management: An International Journal, 17, No. 5, pp. 517-530, 2012.

2 Simchi-Levi, D., Kaminsky, P., Simchi-Levi, E., and Ravi Shankar, "Designing and Managing the supp.ly chain", Tata McGraw Hill Education Private Limited, New Delhi, 2008.

3 Kotha, S., "Competing on the Internet;: The Case ci Amazon.am", European Management journal, 16, No. 2, pp.212222, 1998.

4 Mohammed Haneef AbdulNasiraAndreaGenoveseaAdolf A.AcquayebS.C.L.KohaFredYamoahc, "Comparing linear and circular supp.ly chains: A case study from the construction industry" 183, Part B, Pages 443-457, 2017.

5 Pillai, P, “Amazon.com's Inventory Management”, ICFAI Center for Management Research (ICMR), Hyderabad, India, 2004.

6 Cloutier, G. Muller, D. Verma, R. Nilchiani, E. Hole, and M. Bone, "The concept of Reference Architectures", Syst Eng ,13, No.1, pp. 14-27, 2010.

7 Habib, M.M. "Supply Chain Management (SCM): Theory and Evolution. Supply Chain Management, App.lications and Simulations". InTech Open Access, Croatia, September 2011.

8 Albino, V., Izzo, C. and Kühtz, S, "Input- output models for the analysis of a local/global supp.ly chain", International Journal of Production Economics, 78, No. 2, pp. 119-131, 2002.

9 Florian Kache, Stefan Seuring, "Linking collaboration and integration to risk and performance in supp.ly chains via a review of literature reviews", Supp.ly Chain Management: An International Journal, 19, Issue: 5/6, pp.664-682, 2014.

10 Florian Kache, Stefan Seuring, "Linking collaboration and integration to risk and performance in supp.ly chains via a review of literature reviews", Supp.ly Chain Management: An International Journal, 19 Issue: 5/6, pp.664-682, 2014.

11 Defee, C.C., Williams, B., Randall, W.S. and Thomas, R., “An inventory of theory in logistics and SCM research", International Journal of Logistics Management, 21 No. 3, pp. 404-489, 2010

12 Wantao Yu, Roberto Chavez, Mengying Feng, Frank Wiengarten, "Integrated green supp.ly chain management and operational performance", Supp.ly Chain Management: An International Journal, 19, Issue: 5/6, pp.683-696, 2014.

13 Shiyong Wang, Jiafu Wan, Di Li, and Chunhua Zhang, "Implementing Smart Factory of Industrie 4.0: An Outlook", International Journal of Distributed Sensor Networks , Article ID 3159805, 2016

14 Rashmi N, Uma K M, Jayalakshmi K, Vinodkumar K P, "Big Data Security Challenges: Dealing with too many issues\|", International Journal of Recent Development in Engineering and Technology, 3, No. 2, August 2014.

15 Sanjib Biswas1 and Jaydip Sen "A Proposed Architecture for Big Data Driven Supp.ly Chain Analytics" ICFAI University Press (IUP) Journal of Supp.ly Chain Management, 13, No 3, pp. 7 $34,2016$.

16 F. Tao, Y. Zuo, L. D. Xu, and L. Zhang, "IoT-Based intelligent perception and access of manufacturing resource toward cloud manufacturing," IEEE Transactions on Industrial Informatics, 10, No. 2, pp. 1547-1557, 2014

17 Mohamed Ben-Daya, Elkafi Hassini \& Zied Bahroun (2017): Internet of things and supply chain management: a literature review, International Journal of Production Research, DOI: 10.1080/00207543.2017.1402140

18 Disha H. Parekh, Dr. R. Sridaran , "An Analysis of Security Challenges in Cloud Computing", in International Journal of Advanced Computer Science and App.lications, 4, No.1, 2013.
19 Q. Liu, J. Wan, and K. Zhou, "Cloud manufacturing service system for industrial-cluster-oriented application," Journal of Internet Technology, 15, No. 4, pp. 373-380, 2014.

20 Baburajan, Rajani . "The Rising Cloud Storage Market Opportunity Strengthens Vendors". It.tmcnet.com Retrieved 2011.

21 Gülçin Büyüközkan' and Fethullah Göçer, "Digital Supply Chain: Literature review and a proposed framework for future research", Computers in Industry, 97, Pp. 157-177, May 2018

22 Michael bond, "smart robots" IEEE, 4, Issue: 9, 23 May - 5 June 232009.

23 Pinkava, J., 1989, "Towards a Theory of Sensory Robotics", Robotica, 8, pp. 245-256, 2015.

24 X. Xu, "From cloud computing to cloud manufacturing," Robotics and Computer-Integrated Manufacturing, 28, No. 1, pp. 75-86, 2012.

25 Figueroa, F. and Mahajan, A., "Generic Model of an Autonomous Sensor," Mechatronics, 4 (3), pp. 295-315, 1994.

26 Aramrattana, M., Larsson, T., Jansson, J., \& Englund, C. "Dimensions of cooperative driving, its and automation. In Intelligent Vehicles Symposium (IV)”, 2015 IEEE (pp. 144-149).

27 Kaufui V. Wong and Aldo Hernandez, "A Review of Additive Manufacturing”, International Scholarly Research Network, pp. 1-10, 2012.

28 T. Prabhu , "Modern Rapid 3D printer- A Design Review", International Journal of Mechanical Engineering and Technology, pp. 29-37, 2016

29 Jabbar Qasim Al-maliki, Alaa Jabbar Qasim Al-Maliki , "The Processes and Technologies of 3D Printing", International Journal of Advances in Computer Science and Technology, pp. $161-165,2015$

30 Mosier JN, Smith SL , "Application of guidelines for designing user interface software." In Perlman G, Green GK, Wogalter MS (eds). Human factors perspectives on human-computer interaction: selections from Proceedings of Human Factors and Ergonomics Society annual meetings, 1983-1994. HFES, Santa Monica, CA, pp. 34-37, 1995.

31 Yan, J., Xin. S., Liu, Q., Xu, W., Yang, L., Fan, L., Chen, B. \& Wang, Q,"Intelligent Supply Chain Integration and Management Based on Cloud of Things", International Journal of Distributed Sensor Networks, 1-15, 2014

32 Young-Joon Seo, John Dinwoodie, Dong-Wook Kwak, "The impact of innovativeness on supply chain performance: is supply chain integration a missing link?", Supply Chain Management: An International Journal, 19, Issue: 5/6, pp.733-746, 2014.

33 F. Chen, P. Deng, J. Wan, D. Zhang, A. V. Vasilakos, and X Rong, "Data mining for the internet of things: literature review and challenges," International Journal of Distributed Sensor Networks, 2015.

34 Ganeshan, R, and Harrison Terry P., "An Introduction to Supply Chain Management," Department of Management Sciences and Information Systems, 1995

35 Rabinovich, E. \& Evers, P.T, "Product Fulfillment in Supply Chains Supporting Internet Retailing Operations", Journal of Business Logistics, 24, No.2, pp.205-236, 2003.

36 Kim, Y., Lee, S., \& Samdanis, M. "New Product Development of Wearable Technologies: A Framework of Wearable Epiphanies". Paris: Kent Business School, 2013.

37 Heizer J., Render B, “Operations Management” 6th ed., PrenticeHall, Englewood Cliffs, NJ, 2001 